\title{
DA CIÊNCIA QUALITATIVA À QUANTITATIVA: UMA INCURSÃO PELA HISTÓRIA DA FILOSOFIA
}

João Batista Magalhães Prates

\begin{abstract}
Possui Bacharelado e Licenciatura em Filosofia pela UNIFESP Universidade Federal de São Paulo (2018), pós-graduação em Legislativo, Controle Externo e Políticas Públicas no Brasil pela EGC - Escola de Gestão e Contas Conselheiro Eurípedes Sales, do Tribunal de Contas do município de São Paulo (TCMSP) e Especialização em docência, com ênfase na Educação Básica, pelo Instituto Federal de Minas Gerais (IFMG). Atualmente é bolsista de mestrado do Conselho Nacional de Desenvolvimento Científico e Tecnológico. Tem experiência na área de Filosofia, com ênfase em Ética e Filosofia Política. E-mail: batistaprates1 @ gmail.com
\end{abstract}

\section{RESUMO}

O presente trabalho destina-se a apresentar o percurso histórico da passagem da ciência aristotélica das qualidades para a ciência das quantidades, enxergando nessa transformação um momento essencial para a nossa contemporaneidade do fazer científico. O palco em que se ensaia tal inversão é o Renascimento. Traçaremos alguns passos dessa história, dando ênfase, sobretudo, à revolução de uma disposição ou perspectiva que até então imperava, seguida de uma outra, revolução metodológica, que se deram naquele período e estabeleceram algumas características imprescindíveis à gradual realização da ciência contemporânea.

PALAVRAS-CHAVE: Renascimento. História da Filosofia. Aristóteles e Galileu.

\section{FROM QUALITATIVE TO QUANTITATIVE SCIENCE: AN INCURSION THROUGH THE HISTORY OF PHILOSOPHY}

\begin{abstract}
This article intends to present the historical track in which the Aristotelian science of qualities is supplanted by the rising quantitative one, seeing in this transformation a crucial moment to our contemporary way of making science. The stage in which the transformation takes place is the period called Renascence. We'll rebuild some steps of this history, placing emphasis on the revolution in perspective happened there, followed by a methodological
\end{abstract}


revolution that took place in that period of time and set some of the indispensable characteristics of the nowadays scientific method.

KEYWORDS: Renascence. History of Philosophy. Aristotle and Galilean.

\section{INTRODUÇÃO}

Este texto trata de uma "incursão" por pelo menos dois motivos. Antes de tudo, temos a consciência de que o arco a percorrer é demasiado vasto, de modo que os saltos que daremos excluirão com imprecisão as complexas nuances entre cada momento que destacaremos aqui. Desse modo, sobrevoaremos o tema objetivando uma visão panorâmica do conjunto desse tempo histórico. Trataremos sobretudo do nascimento do método científico. Contemporaneamente, a palavra "ciência" é muito comum para nós. Tão comum que nem nos damos conta que essa palavra tal como a entendemos hoje não esteve dada desde sempre. Foi antes fruto de um longo processo histórico, que articulou técnica, filosofia e religião. A história do significado atual dessas palavras é em boa medida essa história renascentista. Pois bem, isso nos leva ao nosso ponto de partida. Retornaremos aos termos de época, devidamente contextualizados, para visualizar o seu desenvolvimento progressivo. Veremos como que, de Aristóteles, matriz do Renascimento, chegaremos a Galileu, o germe da ciência contemporânea. Para evitar, o máximo que pudermos, o hábito comum de erigir personalidades históricas como marcos pontuais de uma nova era, que sozinhos, mudaram a marcha do mundo, pensamos Galileu como produto de uma nova disposição em frente ao saber que se gestava há algum tempo, no Renascimento; como fruto de um tempo histórico e suas questões.

\section{COSMOS E A CIÊNCIA EM ARISTÓTELES}

Não poderemos tratar do Renascimento sem repassarmos rapidamente a concepção aristotélica de mundo, já que o cosmos aristotélico como que emana a íntima relação que a sua concepção de "ciência" mantinha com a "metafísica". De fato, no projeto de retomada dos ideais antigos, tidos pelos renascentistas como símbolos perfeitos do mais alto grau de desenvolvimento de espírito que a humanidade já alcançou, continuava sendo Aristóteles a autoridade nas matérias do conhecer. Seu Organon compunha uma enciclopédia orgânica, abrangente e coerente com todas as suas partes. Tamanha obra foi reverenciada em sua abrangência e relativa correspondência com as observações casuais cotidianas, aqueles dados mais imediatos à nossa experiência. Junto a ela veio o particular interesse focado em uma Complexitas - Rev. Fil. Tem., Belém, v. 5, n. 1, p. 20-35, jan./dec. 2020 - ISSN: 2525-4154 
postura contemplativa perante o saber, um fator dentre outros que impossibilitou que os gregos aplicassem de ciência à técnica (o que começará a aparecer no Renascimento). É que derivava do cosmos aristotélico uma concepção peculiar de conhecimento (epistême), palavra que traduz o que viemos a conhecer posteriormente por ciência, ao mesmo tempo em que era filosofia (philosophia), como uma e a mesma coisa. De fato, a ciência de que se tratava, para evitar anacronismos, era a filosofia natural, e distinguia-se da filosofia primeira (metafísica) por tratar da physis (natureza) e de seus movimentos e mudanças.

Para explicar a corrupção da matéria que via nas observações casuais cotidianas e a aparente imutabilidade dos céus, por exemplo, Aristóteles foi obrigado a conceber uma cosmologia que dividia o cosmos em duas regiões distintas. $\mathrm{Na}$ esfera inferior (e centro do universo), a Terra, havia imperfeição e corrupção porque tudo o que existe era composto a partir de combinações de quatro elementos corruptíveis (terra, água, ar e fogo). Acima da esfera terrestre estaria a esfera lunar, e uma sequência de esferas cristalinas. Tais corpos celestes eram perfeitos, eternos e incorruptíveis por serem feitos de um quinto elemento não encontrado na Terra, o éter. Inclusive a forma "esfera", o movimento circular e a uniformidade eram axiomaticamente as características perfeitas que só um corpo incorruptível poderia assumir, em oposição ao movimento retilíneo que a matéria imperfeita dos elementos terrestres realizava em sua trajetória de volta ao seu "lugar natural", quando forçada externamente a sair dela. Era trabalho do filósofo natural (ou físico) explicar o comportamento que observamos das coisas materiais na Terra, cabendo ao metafísico (embora esse termo seja mais um anacronismo, tendo sido criado posteriormente por um organizador das obras aristotélicas para designar apenas a posição catalográfica das obras que anexou após os tratados da física), especular a respeito das abstrações do espírito que não encontravam realidade física e não poderiam ser observadas (tal era o estatuto das fórmulas matemáticas, por exemplo, bem como do primeiro motor imóvel, que movimentava todas as esferas celestes, constituindo a causa de seu movimento e de sua existência).

Os movimentos e reações que a matéria realizava se deviam às qualidades inerentes ao material que predominava em sua composição. Os corpos caem porque predominava em sua composição o elemento terra, o qual possuía um desejo natural para cair em direção ao centro do universo; para ir ao seu "lugar natural". Pensava-se em uma natureza viva à época, antropomorfizada. Assim se justificava inclusive o postulado da centralidade da Terra no universo. Para o caso do éter, seria próprio de sua natureza um movimento circular e uniforme, 
bem como a "incorrupção", e todos os pressupostos que se pensava que um corpo perfeito deveria ter. Muito breve e superficialmente, assim Aristóteles concebia o universo e as causas que faziam com que os corpos agissem da maneira que podia-se observar, fossem os movimentos percebidos das estrelas no céu, fossem os movimentos vistos na Terra. Parafraseando Mariconda em O Diálogo de Galileu e a condenação,

Pode-se dizer que as próprias categorias do pensamento estão organizadas em torno da afirmação de nossa posição central no Universo, de modo que a concepção geocêntrica faz parte do núcleo da concepção antropocêntrica da cultura. Percebemos por razões ligadas em parte à estrutura de nossa percepção, em parte a nossa evolução antropológica que a Terra está imóvel no centro do lugar de nossa percepção, ou seja, a imobilidade da Terra assenta-se sobre um conceito de observador ou de sujeito perceptivo ligado ao seu lugar central que se confunde com aquilo que sua percepção lhe informa. Há, portanto, uma unidade entre o geocentrismo e a fenomenologia do sensível espontaneamente praticada por nós. (MARICONDA, 2000, p. 94).

A antítese da filosofia em geral, do conhecimento ou sabedoria (epistemê), para os gregos, estava na technê (traduzida posteriormente por "arte" ou "técnica"). Não devemos entender arte ou técnica pelas acepções comuns que contemporaneamente temos dessas palavras. No contexto grego possuíam um significado bem peculiar. Inclusive, conhecimento e arte no renascimento ainda mantinham o mesmo sentido grego, que foi se modificando gradualmente até adquirir a forma que temos hoje. Isso trataremos no próximo tópico. Quando dizemos "técnica", não nos referimos à habilidade superior que alguém demonstra na realização de sua tarefa, que o destaca entre aqueles outros que fazem uma mesma coisa. Técnica adquire o sentido de "saber fazer", o "saber construir" dos artesãos, embora esse "saber" se distinguisse radicalmente do conhecimento filosófico propriamente dito (ou sabedoria) que deveria incluir o conhecimento das causas daquilo que se faz (creio que não precisamos retomar a doutrina das quatro causas aristotélica); e quando dizemos "arte" no contexto grego, nos referimos às tarefas análogas as do artesão, uma vez que ambas visariam como fim (causa final) algum objeto prático da vida cotidiana comum, física e material, sem o conhecimento das causas.

O sábio filósofo diferenciava-se por ser o único a conhecer inclusive as causas últimas e primeiras das coisas, enquanto havia uma hierarquia entre os artesãos, aos quais cabiam as tarefas mundanas, mas que ainda participavam em alguma medida do conhecimento, e sua posição seria dada pelo objeto de sua arte. A medicina, arte ou técnica (sendo intercambiáveis 
seus sentidos) de produzir saúde, gozava de maior prestígio do que a arte do sapateiro, já que saúde é um objeto superior ao sapato. Pois bem, em tal perspectiva, a vida de mais valor era a do filósofo, que conhecia todas as causas e poderia agora contemplá-las, já que esse conhecimento valia por si mesmo, não por sua utilidade. Nas próprias palavras de Aristóteles, logo no início do Livro I da Metafísica, em 981a 12, lemos:

Entretanto, achamos que o conhecer e o saber pertencem mais à técnica do que à experiência, e julgamos os técnicos mais sábios que os experientes, como se a sabedoria acompanhasse todos eles sobretudo pelo conhecer. Isso porque, uns conhecem a causa, mas outros não: os experientes conhecem o 'que', mas não o 'por que', mas aqueles outros conhecem o 'por que' e a causa. Por isso, em cada domínio, também consideramos que os mestres-de-obra sabem mais e são mais valiosos e sábios que os trabalhadores braçais, porque sabem as causas daquilo que está sendo produzido (ao passo que os últimos, como certas coisas inanimadas, fazem algo, mas fazem sem saber aquilo que fazem - como por exemplo o fogo queima -, mas os inanimados fazem certa coisa devido a certa natureza, ao passo que os trabalhadores braçais fazem por hábito), como se os considerássemos mais sábios não por serem capazes de agir, mas porque dominam a explicação e conhecem as causas. (ANGIONI, s/d)

Logo adiante, no mesmo texto de Aristóteles, em 981b 13, temos que "Quem pela primeira vez inventou uma arte para além das percepções comuns provavelmente deve ter sido admirado pelos homens não apenas porque algum dos achados era útil, mas por ser alguém sábio e diferente dos outros. E, quando outros inventaram mais técnicas, umas para as necessidades, outras para o divertimento, estes, provavelmente, foram considerados mais sábios que aqueles, porque seus conhecimentos não eram voltados à utilidade. " Podemos ver como a concepção de conhecimento digno (filosofia ou ciência) estava para as coisas mais perfeitas e imutáveis nos céus, assim como as técnicas estavam para as coisas corruptíveis da Terra. Veremos que a inversão desse pensamento será caro à história do método científico. De fato, o conhecimento era para ser contemplado, para Aristóteles, e apenas isso, uma vez que tratava das coisas imutáveis e eternamente as mesmas, homem algum poderia modificar algo. A técnica não fazia parte desse conhecimento elevado e nesse deleite, próprio do filósofo, ele viverá a melhor das vidas, se dedicando àquilo que não se limita a nenhuma utilidade prática ou objeto físico.

Havia uma hierarquia de valor estabelecida entre as artes, determinada pelo seu objeto, que determinava um status, posição e prestígio social, de acordo com a maior proximidade ou distância do objeto desinteressado dos filósofos. Essa hierarquia de valor permaneceu de forma Complexitas - Rev. Fil. Tem., Belém, v. 5, n. 1 , p. 20-35, jan./dec. 2020 - ISSN: 2525-4154 
icônica durante o Renascimento e permanece viva ainda hoje, infelizmente; se o homem culto era versado ao conhecimento contemplativo da causa primeira, o monopólio das letras e da erudição cumpria um papel importante nesse sentido, na medida em que aqueles aristoi (os melhores homens) atuavam em um "outro campo" que não aquele da matéria corruptível, e o reflexo desse período começará a ofuscar-se no Renascimento. Apesar do estatuto das artes, havia algo que será caro à história do nosso método científico em Aristóteles, a ser aprofundado no Renascimento, a saber, o pensamento de que todo conhecimento partia da sensação.

É inegável que havia experiência entre os gregos, e em Aristóteles podemos ver muito da disposição do cientista que ainda não nasceu naquela época; era explorador e observador atento de tudo. Mas não foi cientista, como entendemos essa palavra hoje, justamente porque pensou a verdade das coisas a partir de raciocínios a priori. É que o método a ser iniciado com Galileu tem no experimento sua fase mais importante, em cuja verdade se chega somente $a$ posteriori. Mais adiante trataremos um pouco mais especificamente disso. Se formos pensar em graus de conhecimento, no degrau mais baixo estaria o conhecimento das coisas físicas (filosofia natural), que além de partir dos sentidos tinha como objeto o imperfeito e corruptível; logo após tínhamos o conhecimento dos céus, que ainda requeriam dados dos sentidos, ou antes podiam ser observados pelos sentidos, mas já tratavam do incorruptível e imutável, numa zona cinzenta com o conhecimento metafísico, inobservável e que se comprovava por si mesmo pelo raciocínio, eterno e imutável.

\section{ATAQUE PELOS CÉUS}

Tal concepção de mundo imperou por toda a idade média e continuou seu reinado no Renascimento, muito cara à igreja cristã que precisava das ideias aristotélicas para fundamentar seu Deus e a criação descrita na bíblia. Sua cosmologia e a divisão geral dos saberes foram gradualmente superadas no Renascimento, quando começou a buscar não mais no raciocínio a priori a verdade das coisas, mas na própria observação direta dessas coisas (deve-se essa revolução de perspectiva à Tycho Brahe, sobretudo, e que trataremos no próximo tópico), embora o golpe mortal tenha vindo de Galileu, já com o pé na modernidade, quando pensa devidamente o método da ciência moderna, com base em procedimentos matemáticos. Pode ocorrer que exposições imprecisas como essas deem a impressão de que as transformações se deram de maneira rápida logo após as ideias publicadas de algum pensador, que elas foram amplamente aceitas e assimiladas por todos. Na verdade, estamos tratando de um período 
histórico que durou mais de trezentos anos e não poderíamos esgotar as discussões que perpassam a história do desenvolvimento do método científico. Devemos nos contentar em apontar alguns momentos que julgamos de importância cabal. Para uma análise detalhada do quadro da divisão dos saberes, ver Kickhöfel, A Philosophiae partitio de Gregor Reisch. Um mapa para ler o Renascimento, revista Limiar - vol. 2, $n^{\circ} 3$ - $2^{\circ}$ semestre 2014.

Mais familiarizados com a atmosfera, podemos passar à reviravolta do estabelecido no Renascimento, que levou ao progressivo ocaso da física e da metafísica aristotélicas, que desapareceram quase que por completo no século XVIII, levando com elas muito da credibilidade da religião cristã, que foi cada vez mais se fechando em dogmas, assumindo-os como seu fundamento, e fazendo uso da força e da lança para subsistir como instituição, negando a conduta moral de sua própria doutrina em sua atuação histórica, se fazendo presente e sempre ao lado da opressão e da escravidão capitalista mundo afora, como um instrumento seu. Mas se pensamos que os pensadores Renascentistas foram grandes hereges que não viam na religião mais do que mitos primitivos e queriam a sua extinção, estaremos profundamente enganados. É contemporâneo demais esse sentimento de incompatibilidade entre a religião e a ciência, e podemos investigar o quanto disso resulta do nosso hábito ocidental de pensar o cristianismo e as narrações bíblicas fantasiosas como sendo a única religião existente e quiçá possível. Copérnico (1473-1543), Tycho Brahe (1546-1601), Galileu (1564-1642), Kepler (1571-1630), todas essas grandes figuras, as mais conhecidas do Renascimento, que foram desmontando o sistema aristotélico pouco a pouco, em golpes sucessivos (ora em algum aspecto de sua concepção cosmológica, ora em outro aspecto, na física, ora em uma disposição ou comportamento), foram cristãos exemplares. Não havia motivo algum para questionar a sua fé. Inclusive, Tycho Brahe, numa célebre carta a Kepler, condena a cosmologia Copernicana por ser contrária às escrituras, ao mesmo tempo em que manifesta sua desaprovação à tendência que Kepler mostrava em adotar as ideias copernicanas, como se lê na carta:

Eu não aprovo aquilo que no teu engenhoso escrito se mostra, entre outras coisas, como um erro comum, o de atribuir realidade às órbitas celestes. Por esta via, ordenas prontamente as imaginações copernicanas e, desse modo, não negarei que subscreves facilmente os movimentos celestes obterem uma certa simetria, à qual subjazem razões para os planetas moverem-se ao redor de um centro com distância diferente do Sol ou da Terra; mas as proporções das disposições e a harmonia são dadas a posteriori pelos movimentos quando as suas ocorrências se apresentam e, ao contrário, não se pode pretender que são dadas a priori, tal como tu e Mästlin querem, e elas são difíceis de encontrar. Se 
alguém realizar essa obra, direi que superou aquele antigo Pitágoras, o qual pressentiu que a harmonia celeste bem-ordenada estava profundamente em todo o mundo. Pode-se dizer que os movimentos circulares no céu não poucas vezes produzem as mais variadas figuras angulares e, devido a seu movimento composto, muitas vezes oblongas; e examinando atentamente algumas, é possível ver que isso se faz por acidente, e a razão abomina essa suposição. Com efeito, é oportuno que os circuitos dos astros sejam compostos todos por círculos; aliás, não retornariam perpetuamente de modo uniforme e igual [para o mesmo lugar] e frustrariam, assim, a perenidade; de outro modo, seriam tanto menos simples e mais anômalos, não se acomodando nem ao uso, nem à doutrina. (BRAHE, 2004, pg. 94).

Algumas considerações fazem-se oportunas para explicar um pouco do denso conteúdo da passagem, que remete às principais questões em torno de Copérnico, nossa primeira figura a ser considerada no período, e das demais repercussões nos pensadores posteriores (sobretudo em sua disposição e maneira de ver o mundo) e em suas obras. Coube a Copérnico a tarefa de reordenar a ordem dos astros devido a problemas matemáticos internos dos sistemas tentados anteriormente a partir dos axiomas aristotélicos. Como o próprio Copérnico dirá em seu prefácio de As revoluções dos orbes celestes, dedicado ao Sumo Pontífice Paulo III,

Nenhum outro motivo me levou e pensar num método diferente de calclar os movimentos das esferas do Universo senão o facto de ter verificado que os matemáticos não estão de acordo consigo próprios na investigação de tais movimentos. É que em primeiro lugar eles se encontram de tal maneira inseguros quanto ao movimento do Sol e da Lua que nem a duração regular do ano corrente são capazes de explicar e formular. Em segundo lugar, ao determinarem os movimentos das esferas do Universo e dos cinco planetas não usam até dos mesmos princípios e premissas que nas demonstrações dos movimentos e revoluções aparentes. Com efeito, uns apenas se servem de círculos concêntricos e outros de círculos excêntricos e epiciclos com os quais, porém, não atingem completamente o que pretendem (...) Andando eu, pois, há muito tempo a meditar comigo nesta incerteza dos ensinamentos tradicionais das matemáticas acerca da dedução dos movimentos das esferas do Universo, começou a desgostar-me o facto de os filósofos não terem conhecimento firme de nenhuma explicação da máquina do Mundo que por nossa causa fora construída pelo mais qualificado e modelar artista de todos, eles que, aliais, fazem afinal profundas investigações a respeito das mais minuciosas coisas deste Universo (...) Assim, aproveitei, desde logo a oportunidade e comecei também eu a especular acerca da mobilidade da Terra. E embora a ideia parecesse absurda, contudo, porque eu sabia que a outros antes de mim fora concedida a liberdade de imaginar os círculos que quisessem para explicar os fenômenos celestes, pensei que também me fosse facilmente permitido experimentar se, uma vez admitido algum movimento da Terra, poderia encontrar demonstrações mais seguras do que as deles para as revoluções das esferas celestes. (COPÉRNICO, s/d) 
Ele buscará "salvar as aparências" já que a física aristotélica não concordava com o que se via nos céus e isso era um grande empecilho para os fins práticos, principalmente para o calendário; Mariconda explica que "No plano científico, com Copérnico, o movimento do observador passa a ter uma função radical ou primitiva, de modo que 'salvar as aparências' quer dizer agora restaurar sob as aparências os princípios da física que as explicam e que, portanto, tornam possíveis essas aparências. Em suma, na astronomia de Copérnico existe uma pretensão de explicação que invade o terreno que a tradição havia reservado à filosofia natural, donde a confusão entre as artes liberais apontada por Osiander.” (CAMPINAS, p. 94, 2000).

Surgia o modelo heliocêntrico copernicano. Apesar das "boas intenções" do aristotélico Copérnico, que em última instância manteve a autoridade aristotélica até o final, defendendo os seus postulados metafísicos por detrás da sua concepção física. Contudo, o "simples" fato de mudar a Terra de lugar no universo desmontaria o sistema orgânico de Aristóteles, como se derruba um castelo de cartas ao retirar qualquer uma delas.

De fato, postular a centralidade da Terra no universo era um caro axioma e não haveria como salvaguardar o resto do sistema dos sucessivos ataques que se seguiriam. A igreja jamais autorizaria a publicação de "As Revoluções das Orbes Celestes" de Copérnico, não fosse um prefácio habilmente escrito por Oisander (ao qual já aludimos anteriormente). Esse personagem entrou para a história e se eternizou como uma peça fundamental (o livro de Copérnico só seria condenado após sua morte - e a ampla leitura dos militantes revolucionários da ciência). A habilidade de Oisander consistiu, sobretudo, na ênfase que deu, no prefácio falso que redigiu para a obra, sobre a diferença entre o matemático (a matemática gozava do estatuto de arte, tal como entendida pelos antigos) e o filósofo.

O livro tratar-se-ia então apenas de dados matemáticos que nada versariam a respeito da natureza última das coisas, se contentando em calcular as distâncias e as proporções dos corpos celestes, pela beleza em si de um ideal de perfeição que se estendesse para além do estranhamento que a experiência sensível dos fenômenos celestes conferia. Passava despercebido pela censura religiosa as ideias que abalariam profundamente todo o corpus aristotélico, começando pelo ataque ao geocentrismo; mudando os lugares da Terra e do Sol no cosmos aristotélico. Citando uma vez mais Mariconda: "a tese copernicana do movimento da Terra, ao descentralizar o observador e colocá-lo em movimento, terá um impacto de fundamental importância sobre o conjunto especificamente organizado da cultura, opondo-se 
diretamente ao conjunto do saber, da ciência, da religião e da opinião comum." (MARICONDA, 2000, p. 94).

\section{DA VIDA CONTEMPLATIVA À VIDA ATIVA}

A postura empírica propriamente dita, na astronomia, começa com Tycho Brahe, posteriormente. Só ele se voltará aos céus para fazer novas observações, não mais apenas trabalhando com as já feitas e organizadas pelas "autoridades" da época. Ele criticará o modelo heliocêntrico de Copérnico e imaginará um novo modelo, o chamado "modelo híbrido", para explicar os movimentos dos corpos celestes. Podemos dizer que com Tycho presenciaremos a revolução de uma perspectiva que se fazia viva e presente ainda em Copérnico, explicitada no método de construção do saber a partir de um sistema geométrico imaginado a priori que, tomado como certo, nos levaria à observação empírica da realidade (a experiência propriamente dita) em um segundo momento com a intenção residual de contemplar a verdade anteriormente estabelecida, tentando adequar a realidade ao imaginado. Atuava exatamente esse projeto “contemplativo" em Copérnico, estando o caminho ao conhecimento das coisas já indicado de uma vez por todas pelas palavras de autoridade de Aristóteles. Se nossos olhos não enxergam na realidade os movimentos descritos é porque algo está errado com nossos olhos, que só podem nos dar a aparência das coisas.

Tycho propõe, pelo contrário, que na busca pelo modelo cosmológico verdadeiro, devase partir da observação e ela se bastaria a si mesma para nos mostrar a verdade como ela é, em uma espécie de realismo ingênuo. Mesmo que Tycho criticasse Copérnico, atuava em ambos uma mistura do novo com o antigo, mas em sentidos diversos. Ele tampouco estava livre de contradições, e esse fato nos permite entrever que um processo só se dá a partir de tudo aquilo que atua em seu contexto histórico, um novo que nasce das entranhas do antigo. É que ainda ele assumia ainda alguns axiomas a priori, que deveriam forçar a realidade à sua correspondência. As duas notas referentes à citação anterior da carta à Kepler é uma explicação sintética perfeita. Transcrevo-as:

Nesse período específico da história da astronomia, o copernicanismo, por não ser dado diretamente aos sentidos, isto é, ninguém vê ou sente a Terra se movimentar, é visto por Brahe como uma imaginação, fruto de imagens construídas na mente que, à primeira vista, não tem relação alguma com as experiências. De fato, o copernicanismo é conceitual; representa-se intelectivamente o mundo proposto por Copérnico. Isso aponta para uma das grandes dificuldades pelas quais esse programa nascente passou: permitir resolver os problemas empíricos e, ao mesmo 
tempo, dar explicações que têm como base conceitos que não podem ser comprovados diretamente pelos sentidos (...) Essa exposição [...]' mostra um dos problemas filosóficos de Brahe. Por um lado, ele é um ardoroso defensor da astronomia observacional, defendendo a construção de teorias a partir da experiência; por outro lado, entretanto, rejeita qualquer fuga ou ruptura com o axioma platônico de movimentos circulares e uniformes ou compostos desses; as curvas oblongas que os planetas fazem são 'acidentais', não 'servindo nem ao uso, nem à doutrina'. O interessante é que, mesmo defendendo a astronomia observacional, Brahe não mudou, nesse caso, o apego conceitual à circularidade e uniformidade. (STUDIA, 2004, pg. 567-74).

Tamanho trabalho intelectual dos astrônomos na época, os quais eram considerados meros matemáticos até então (estando para os pedreiros assim como os filósofos estavam para os mestres de obra), paralelamente à atuação revolucionária na dos médicos no campo da anatomia, nasciam manifestações que começavam a transparecer uma nova disposição perante o saber que surgia progressivamente à época. Gradualmente aqueles não-filósofos ligados à arte em geral começam a sobressair-se pela sua atuação em suas áreas e começam a pensar questões do método em sua própria arte; os mais eruditos começavam a escrever tratados sobre as suas artes, numa união entre as palavras e as técnicas.

Já dissemos que o conceito de arte no Renascimento mantinha a concepção expressa no quadro do Reisch, em continuidade com a concepção aristotélica que vigorou por toda Idade Média. Mas com a revolução de perspectiva que modificou a postura perante o saber, gradualmente aparece o sentido de "autoria" que significava progressivo reconhecimento e modificação de status do artesão. As atividades manuais clamam por reconhecimento e, por que não, autoridade. Uma insurreição silenciosa contra a "palavra de ordem" das autoridades (os filósofos), que colocava necessariamente fora de questão tudo aquilo que contradizia as escrituras aristotélicas! É importante notar a postura em frente ao conhecer, que tinha por trás o novo valor da vida ativa, em oposição à atitude anterior, da vida contemplativa.

Um exemplo de época se faz oportuno: nas aulas de anatomia, o filósofo, ocupava seu suposto lugar de saber, em destaque e acima dos seus demais discípulos, com toda a sua superioridade característica do status que gozava por dominar a palavra daquele que conhecia as causas de todas as coisas e poder passá-la adiante aos versados eruditos e iniciados em filosofia, que de forma passiva, se servindo de um trabalhador braçal (o detentor da técnica). Contemplariam no corpo aquilo que foi escrito sobre ele, enquanto para abrir os corpos sujamse as mãos de homens que nada daquilo poderiam entender. Isso tudo cede lugar à figura do experimentador, aprendiz da prática do fazer, erudito manual renascentista que, em rebelião Complexitas - Rev. Fil. Tem., Belém, v. 5, n. 1 , p. 20-35, jan./dec. 2020 - ISSN: 2525-4154 
contra a autoridade filosófica, pretendia apreender a verdade a posteriori das coisas condizentes à sua arte de forma ativa, o que preparava os passos posteriores em direção à ciência tal qual a conhecemos hoje.

\section{GALILEU E A REVOLUÇÃO DO MÉTODO: O INSTRUMENTO E A NOVA CONCEPÇÃO DE NATUREZA}

Coube a Galileu reunir e sistematizar todo esse espírito da época, o direcionando de tal modo a estabelecer algo completamente novo em relação aos pensadores que o antecederam. Postulará também uma autossuficiência dos sentidos, ao mesmo tempo que uma necessidade de corrigi-los (devido às aparências enganosas), mas o método para corrigi-los será não mais a autoridade das escrituras, mas uma investigação a posteriori dos fatos, pelos próprios sentidos, em situações controladas. Nascia a ideia de experimento, na esteira da postura ativa perante o conhecimento, na medida em que Galileu começou a construir diversos instrumentos para aumentar o alcance e a precisão dos sentidos e esses instrumentos começaram a ser usados em conformidade com a nova epistemologia que ele viria a formar. Mariconda, em Galileu e a ciência moderna pontua bem isso.

A tendência a uma atitude ativa está particularmente exemplificada em Galileu por seu interesse no desenvolvimento de instrumentos científicos. Logo no início de sua carreira científica, no biênio 1586/87, esse interesse está presente na invenção da balança hidrostática (GALILEI, 1929; 1986). Trata-se, na verdade, de um instrumento destinado a resolver o problema prático de medição de uma grandeza física: o peso específico dos materiais, tal como definido pelo divino Arquimedes em seu tratado. Dos corpos flutuantes. Essa preocupação com o aspecto prático da ciência manteve-se durante os treze anos seguintes; primeiro, numa direção eminentemente técnica com o compasso geométrico-militar e, a partir de 1609, em uma direção claramente científica com o telescópio. (MARICONDA, 2006, p. 270).

Espanta verificar a filiação, desde as origens, dos primeiros instrumentos que aplicavam conhecimentos matemáticos com a guerra. Tais instrumentos que, de início, serviam a fins práticos, progressivamente foram usados na investigação em filosofia natural, apontando para uma nova forma de conceber a natureza inaugurada por Galileu. Se Copérnico ainda foi aristotélico, no sentido de que buscou alternativas no interior da lógica aristotélica das qualidades inerentes à matéria, Galileu dará o passo adiante ao postular uma concepção de matéria inerte e morta, passível à matematização. Isso foi possível, entre outras coisas, pelas 
suas observações que fez da lua e dos satélites de Júpiter, graças ao telescópio que construiu a partir de uma luneta já existente, possivelmente usada com fins práticos militares de avistamento de inimigos a longa distância. Essas investigações com o telescópio lhe proporcionaram evidências das crateras na Lua, as quais ele relata no Sidereus Nuncius, razão pela qual pode inferir a inexistência do éter aristotélico. Se a matéria dos corpos celestes é igualmente corruptível e não tinha nada de uniforme, cristalina e perfeita, sua matéria deveria ser a mesma que a da Terra.

Antes dele, pela aplicação de conhecimentos de óptica, Da Vinci já demonstrava a semelhança entre a Lua e a Terra a partir da observação do brilho que ela emitia, como resultado do reflexo da luz vinda da Terra em direção à Lua. Galileu será um fiel defensor do copernicanismo. A época assistiu a progressiva passagem do geocentrismo antigo ao heliocentrismo, mas não sem muita resistência por parte da igreja. É que mudar o lugar da Terra era atacar duramente as bases da física aristotélica, e ter de responder à necessidade de erigir uma nova física, bem como uma nova metafísica. A teologia estava em risco. Oisander, conhecido de Copérnico que ficou encarregado de levar seus escritos à publicação, anteviu bem isso e, no prefácio que forjou para a obra daquele, fingindo ser o próprio autor, livrou Copérnico do impedimento da igreja e suas ideias puderam circular. A condenação do seu livro só veio depois de sua morte, mas já era tarde: um bom número de pensadores havia tido contato com suas ideias e iniciavam já o processo revolucionário. Estava ruindo o edifício aristotélico dos cinco elementos, centro de toda a sua física.

Devia-se pensar uma nova concepção de natureza para a nova física. Nascia a concepção contemporânea de natureza como um mecanismo perpassado por forças naturais, regido por leis matemáticas, junto com o método para lidar com ela. A matemática se apresentava como a chave para a leitura dos fenômenos da natureza. Isso só foi possível graças à divisão que Galileu empreende nos dados dos sentidos. Uma passagem de $O$ ensaiador, de Galileu, explicita de forma concisa:

Portanto, afirmo estar bem em condição de sair deste aperto, concebendo uma matéria ou substância corpórea, como termo e aspecto daquela ou outra substância, grande ou pequena em relação a outras, colocada naquele ou neste lugar, naquele ou neste tempo, movimento ou parada, em contato ou não com outro corpo, como sendo única ou poucas ou muitas, nem posso imaginá-la de forma alguma separada destas condições; porém não consigo, mesmo esforçando-me, imaginála branca ou vermelha, amarga ou doce, sonora ou muda, perfumada ou não, considerando-a possuidora destas características: pelo contrário, se 
não possuíssemos os sentidos para nos ajudar, o raciocínio ou a imaginação não chegariam nunca a alguma conclusão. Assim, eu considero que estes cheiros, sabores, cores, etc, em relação ao sujeito onde nos parecem residir, não são outra coisa que puros nomes, mas residem em vez no corpo sensitivo, porque se tiramos a animação todas as outras qualidades anulam-se completamente; havendo nós imposto a ele nomes característicos e diferentes dos outros acidentes, acidentes primários e reais, é como se quiséssemos acreditar que estas qualidades sejam verdadeira e realmente diversas das outras. (GALILEI, 1983, p. 239)

Cuidou dessa maneira de separar na matéria as qualidades primárias (forma, figura, número, movimento e contato) das qualidades secundárias (cor, odor, sabor e som). Ele postulará que apenas as qualidades primárias da matéria podem ser objeto da filosofia natural, pois as segundas estão no sujeito cognoscente e não podem nos fornecer a precisão matemática na experimentação. Abandonava-se paralelamente a investigação pelas causas últimas, que não poderiam ser objeto da ciência que nascia, embora Galileu ainda cresse na necessidade da metafísica.

Estabelece-se uma cisão, portanto, na filosofia, em dois campos separados e distintos, a filosofia natural e a metafísica, sendo que a primeira não estava mais submetida à autoridade da segunda, puramente especulativa, imprecisa e inverificável. Erigia-se assim uma nova divisão dos saberes, com a cara ideia de autonomia para cada campo de conhecimento que ele desenvolverá, e as artes passarão a gozar de uma posição privilegiada no interior da filosofia natural

Ao mesmo tempo, Galileu era um religioso; tudo isso não impediu que a igreja mantivesse a sua autoridade. É que o fato de a filosofia natural ser agora autônoma em relação à metafísica significava apenas que ambos os campos de conhecimento, por tratarem de objetos distintos, não poderiam transferir suas exigências metodológicas ao outro, e deveriam progredir por conta própria. Entendidos dessa maneira, não eram incompatíveis de forma alguma. Nas palavras de Mariconda, novamente:

A resposta de Galileu ao problema da suposta incompatibilidade entre a teoria de Copérnico e a Bíblia consiste, pois, em considerar primeiramente que, nos assuntos naturais, não pode ser atribuída às Escrituras uma autoridade superior àquela da própria natureza (GALILEI, 1932 [1613-1616], p. 283; 1988, p. 19). Como, além disso, a ciência matemática da natureza possui um método independente (autônomo) de aferir a verdade e de chegar a decisões racionais nas polêmicas acerca de questões naturais, ela não precisa apoiar-se em nenhuma autoridade exterior a sua própria esfera de competência. A 
autonomia da ciência está, assim, assentada numa tese de suficiência do método científico para aferir a verdade das teorias naturais mediante um escrutínio crítico baseado em "experiências sensíveis" e "demonstrações necessárias", estas últimas identificadas por Galileu com o raciocínio demonstrativo matemático. (MARICONDA, 2006, p. 284).

Estavam lançadas as bases para o ocaso da metafísica aristotélica, a partir do tratamento matematizado da natureza e da falta de interesse naqueles estudos inverificáveis e que nada têm de (aparente) utilidade prática; não interferem diretamente na vida. Todas observações dos céus à época não se inseriam mais numa perspectiva de saber pelo saber. Inicia-se com ele a separação de filosofia natural (que viria a tornar-se ciência experimental) e filosofia (especulativa). Aquela já não trataria de uma matéria possuidora das quatro causas aristotélicas e dotadas de espírito, mas apenas de uma causa material, estando não mais subordinada à metafísica, autônoma para buscar a sua própria verdade, naquelas coisas que lhe dizem respeito.

A ciência qualitativa, portanto, foi aquela que prescindia e era determinada pela metafísica, que lidava com uma natureza antropomorfizada e cheia de qualidades próprias inerentes. Tal "fazer científico" era orientado para a contemplação, o que tornava absurda a ideia de interferir na natureza. A ciência qualitativa nascente reduz toda a natureza à condição de matéria morta passiva, desprovida de qualquer interioridade, perpassada por forças externas a ela e que determinam seu movimento através de relações causais e mecânicas entre si e a matéria circundante. Tal é a nossa concepção de natureza até os dias de hoje.

\section{CONSIDERAÇÕES FINAIS}

Quisemos aludir com esse trabalho que na separação de Galileu entre a metafísica e a filosofia natural tínhamos um estado de coisas em que nenhum dos dois campos de saberes autônomos poderia exigir do outro a aplicação de seu próprio método em suas investigações; não poderiam ser a medida de correção um do outro por tratarem de objetos diferentes. Para tanto, voltamos atrás e tentamos entender como surgiu a ideia imperante (e muito funcional) de fazer ciência como a fazemos hoje; a história remonta ao Renascimento, mas como vimos, antes ainda.

É que na época imperava uma forte herança antiga que se impunha como paradigma (e até palavra de ordem) para se pensar a natureza e a vida em geral. Vimos muito brevemente como um quadro de organização dos saberes foi-se desmantelando até a progressiva Complexitas - Rev. Fil. Tem., Belém, v. 5, n. 1, p. 20-35, jan./dec. 2020 - ISSN: 2525-4154 
autonomia do fazer científico, que tateante, abandonou lucubrações em favor de uma prática que produzia resultados práticos. Vida ativa, naquele contexto fecundo se formou o germe da concepção que, de fato, foi sistematizada e exibida na modernidade do século XVIII, tendo o seu mais alto grau de desenvolvimento hoje.

Tomamos Galileu por objeto de estudo uma vez que é atribuído a ele (e com muita justiça) o título de inventor do método científico. Galileu tinha bem claro que o espaço cabido à ciência era diverso do da metafísica. Com ele abandona-se o discurso da autoridade dogmática no âmbito da Filosofia, em um contexto impulsionado pela pretensão prática de tornar a vida melhor e mais fácil, aumentando a potencialidade de ação humana no mundo, pela aplicação de conhecimentos científicos à técnica (o que teria um duplo efeito de resultar em tecnologia que facilitasse a vida e em conhecimento a engrandecer o homem e sua obra).

\section{REFERÊNCIAS BIBLIOGRÁFICAS}

MARICONDA, Pablo. O diálogo de Galileu e a condenação, in Cadernos de Hististória e Fiosofia da Ciência, Série 3, v. 10, n. 1, jan.-jun, pg 77160. Campinas, 2000.

ARISTÓTELES. Metafísica, Livros I-II-III, tradução de Lucas Angioni. Disponível em https://www.academia.edu/12441153 /Metaf\%C3\%ADsica_I-II-III_Alpha$\% \mathrm{CE} \% \mathrm{~B} 1-B e t a \_(u ́ l t i m o \text { acesso no }$ dia 21/02/2018).

KICKHOEFEL, Eduardo Henrique. A Philosophiae partitio de Gregor Reisch. Um mapa para ler o Renascimento, in Revista Limiar vol. $2, \mathrm{n}^{\mathrm{o}} 3-2^{\mathrm{o}}$ semestre 2014, pg. 85-115. Departamento de Filosofia da UNIFESP, Guarulhos.
BRAHE, Tycho. Carta de Tycho Brahe a Johannes Kepler em Graz, in Revista Scientiae Studia, São Paulo, v. 2, n. 4, p. 567-74, 2004.

COPÉRNICO, Nicolau. As revoluções dos orbes celestes, Edição da Fundação Calouste Gulbenkian, s/d.

MARICONDA, Pablo. Galileu $e$ a Ciência Moderna, in Cadernos de Ciências Humanas - Especiaria. v. 9, n.16, jul./dez., 2006, pg. 267-292. Revista da Universidade Estadual de Santa Cruz (UESC).

GALILEI, Galileu. Sidereus Nuncius. Terceira edição da Fundação Calouste Gulbenkian, s/d.

PRATES, J. B. M. Da Ciência Qualitativa à Quantitativa: Uma Incursão pela História da Filosofia. Complexitas - Rev. Fil. Tem. Belém, v. 5, n. 1, p. 20-35, jan./dec. 2020. Disponível em: http://www.periodicos.ufpa.br/index.php/complexitas/article/view/7676>. Acesso em: 01 de novembro de 2020. 